or neither should be. The first option is impractical and the second inadvisable given that some products could be harmful.

\section{A FRESH START}

It is time to reset the debate. Product-versusprocess arguments reflect world views about the desired level of regulation for GE organisms. These underlying viewpoints should be made explicit, and the idea that productbased regulation is the only science-based approach rejected.

In reality, it is impossible to be completely 'science based' in a regulatory system. Value judgements are embedded in all risk and safety assessments. For example, the doseresponse curve for a certain food additive might be known, but such data do not by themselves tell regulators where to set an acceptable safety limit. More often, the dose-response curve is not well established, or known at all. This uncertainty leads to various interpretations of the data.

Empirical evidence matters, but human interpretation brings meaning to that evidence, and multiple perspectives can strengthen understanding. Thus, an oversight system should focus on what concerns a diversity of stakeholders and citizens have, what evidence or risk-mitigation strategies can help to address those concerns, and what classes of GE products or processes should receive greater regulatory scrutiny. In practice, regulators and other stakeholders will need to consider a mix of product and process issues to capture product groups that are likely to be of greater concern.

Several models in the social-science literature describe how such democratic deliberation might be achieved ${ }^{6}$. And Norway's decision-making about GE organisms under its gene-technology act demonstrates how factors outside 'science-based' health or environmental harms can be incorporated into formal regulatory processes in practice. Since 2005, regulators in Norway making decisions about whether a GE organism will be released into the environment consider the results of safety reviews, and whether participants of a consultation process perceive that the organism provides a better option than alternatives and contributes to sustainable agricultural practices (see go.nature.com/5nxzcn).

There is a chance to start over, in the United States and elsewhere. In part because of advances in gene editing and a greater diversity of GE organisms being presented to regulators, the OSTP initiated a process in
July 2015 to clarify which regulatory authority is responsible for what under the $\mathrm{CFRB}^{7}$. And just last month, the USDA published four possible scenarios for a proposed new framework for the regulation of GE crops ${ }^{8}$.

Within these efforts and others, stakeholders could do away with polarizing product-versus-process and science-versusvalues framings, and help to establish a governance system that is both informed by the science and guided by the concerns and values of citizens.

Jennifer Kuzma is distinguished professor in the social sciences and co-director of the Genetic Engineering and Society Center at North Carolina State University, USA.

e-mail:jkuzma@ncsu.edu

1. OSTP. Fed. Reg. 51, 23302 (1986).

2. Potrykus, I. N. Biotechnol. 27, 466-472 (2010).

3. Wolt, J. D., Wang, K. \& Yang, B. Plant Biotechnol. J. 14, 510-518 (2015).

4. Huang, S., Weigel, D., Beachy, R. N. \& Li, J. Nature Genet. 48, 109-111 (2016).

5. Kokotovich, A. \& Kuzma, J. Bull. Sci. Technol. Soc. 34, 108-120 (2014).

6. Ramachandran, G. et al. J. Nanopart. Res. 13, 1345-1371 (2011).

7. Waltz, E. Nature Biotechnol. 33, 1221-1222 (2015).

8. USDA. Fed. Reg. 81, 6225-6229 (2016).

\title{
Learn from DIY biologists
}

\section{The citizen-science community has a responsible, proactive attitude that is well suited to gene-editing, argues Todd Kuiken.}

$\mathrm{O}$ ne of the top science stories of 2012 involved a furore about the wisdom of enhancing the transmissibility of the H5N1 avian influenza virus in ferrets. In that same year, fears mounted that do-it-yourself (DIY) biologists would cook up their own versions of the virus using information published in the academic press.

Now, journalists and others are again targeting the citizen-science community - a group of people with or without formal training who pursue research either as a hobby or to foster societal learning and open science - amid fears about the nascent gene-editing technology CRISPR-Cas9. In January, the San Jose Mercury News ran an article under a pearl-clutching headline: "Bay Area biologist's gene-editing kit lets do-it-yourselfers play God at the kitchen table." And although they are much less alarmist, scholars are advising policymakers to consider the potential uses of gene editing "outside the traditional laboratory setting" (R. A. Charo \& H. T. Greely Am. J. Bioeth. 15, 11-17; 2015).

The reality is that the techniques and expertise needed to create a deadly insect or virus are far beyond the capabilities of the typical DIY biologist or community lab. Moreover, pursuing such a creation would go against the culture of responsibility that DIY biologists have developed over the past five years. In fact, when it comes to thinking proactively about the safety issues thrown up by biotechnology, the global DIY-biology community is arguably ahead of the scientific establishment.

\section{EASY ACCESS}

The equipment and reagents that are needed to use CRISPR-Cas9 are already readily available to DIY biologists. Members of the teams that participated in the 2015 International Genetically Engineered Machine (iGEM) competition - including high-school students and users of community labs around

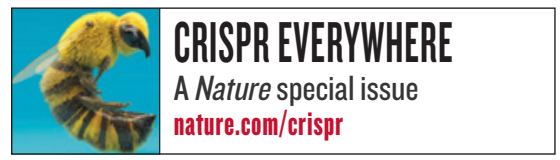

the world - received CRISPR-Cas9 plasmids in their starting kits. These kits contain more than 1,000 standard biological parts known as BioBricks, the DNA-based building blocks that participants need to engineer a biological system for entering into the competition. Other components of the CRISPR-Cas9 system are also available from the iGEM registry (http://parts.igem.org/CRISPR).

Yet few DIY biologists seem to be using the technology. Both Tom Burkett, founder of the Baltimore Under Ground Science Space in Maryland, and Ellen Jorgensen, executive director of Genspace - a community lab in Brooklyn, New York - say that their users are interested in CRISPR-Cas9, and Genspace will be offering a workshop on it in March. But none of the projects currently being pursued in these spaces require it. Users of the La Paillasse community lab in Paris are similarly focused on projects that do not need CRISPR-Cas9.

The materials might be available, but the knowledge and understanding needed to make edits that have the desired effects 
